\title{
Article \\ Enhanced Energy Savings with Adaptive Watchful Sleep Mode for Next Generation Passive Optical Network
}

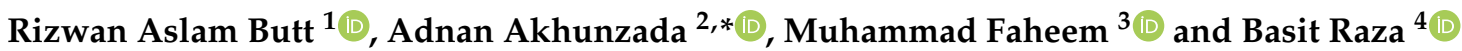 \\ 1 Department of Telecommunications Engineering, NED University of Engineering, Karachi 75220, Pakistan; \\ rizwan.aslam@neduet.edu.pk \\ 2 Faculty of Computing and Informatics, University Malaysia Sabah, Kota Kinabalu 88400, Malaysia \\ 3 Department of Computer Engineering, Abdullah Gul University, Kayseri 38080, Turkey; \\ muhammad.faheem@agu.edu.tr \\ 4 Department of Computer Science, COMSATS University Islamabad (CUI), Islamabad 45550, Pakistan; \\ basit.raza@comsats.edu.pk \\ * Correspondence: adnan.akhunzada@ums.edu.my
}

check for updates

Citation: Butt, R.A.; Akhunzada, A.; Faheem, M.; Raza, B. Enhanced Energy Savings with Adaptive Watchful Sleep Mode for Next Generation Passive Optical Network. Energies 2022, 15, 1639. https:// doi.org/10.3390/en15051639

Academic Editor: Anna Pinnarelli

Received: 11 December 2021

Accepted: 26 January 2022

Published: 23 February 2022

Publisher's Note: MDPI stays neutral with regard to jurisdictional claims in published maps and institutional affiliations.

Copyright: (c) 2022 by the authors. Licensee MDPI, Basel, Switzerland. This article is an open access article distributed under the terms and conditions of the Creative Commons Attribution (CC BY) license (https:// creativecommons.org/licenses/by/ $4.0 /)$.

\begin{abstract}
A single watchful sleep mode (WSM) combines the features of both cyclic sleep mode (CSM) and cyclic doze mode (CDM) in a single process by periodically turning ON and OFF the optical receiver $(\mathrm{RX})$ of the optical network terminal (ONT) in a symmetric manner. This results in almost the same energy savings for the ONTs as achieved by the CSM process while significantly reducing the upstream delays. However, in this study we argue that the periodic ON and OFF periods of the ONT RX is not an energy efficient approach, as it reduces the ONT Asleep (AS) state time. Instead, this study proposes an adaptive watchful sleep mode (AWSM) in which the RX ON time of ONT is minimized during ONT Watch state by choosing it according to the length of the traffic queue of the type 1 (T1) traffic class. The performance of AWSM is compared with standard WSM and CSM schemes. The investigation reveals that by minimizing the RX ON time, the AWSM scheme achieves up to $71 \%$ average energy saving per ONT at low traffic loads. The comparative study results show that the ONT energy savings achieved by AWSM are $9 \%$ higher than the symmetric WSM with almost the same delay and delay variance performance.
\end{abstract}

Keywords: energy efficient PON; watchful sleep mode; passive optical network; cyclic sleep

\section{Introduction}

The ever-growing use of the Internet in our daily lives is constantly pushing the demand for higher capacity and high-performance optical core [1] and access networks [2]. The International Telecommunication Union (ITU) 2020 report [3] shows that Internet access at homes increased by $10 \%$ compared to 2019. Especially in the developed countries such as Europe, $96 \%$ individuals were recorded to be regular Internet users. Moreover, the COVID-19 pandemic has further accelerated broadband subscriptions by $33 \%$ and bandwidth usage growth rate was $6 \%$ higher compared to 2019. The emergence of smart televisions is expected to further accelerate the demand of fixed broadband connections that can offer triple-play: voice, video, and data services. Passive optical networks (PONs) have revolutionized the access network (AN) and overcome the bandwidth barriers imposed by copper media [4] in the provisi oning of high-speed fixed broadband services such as VDSL and HDSL. The PON has the capability to offer triple-play services to both residential and commercial users through a fiber to the home (FTTH) network topology with per-user data rates of $150 \mathrm{Mbps}$ and above. It provides low cost, faster, and more reliable services compared to both the copper AN and the active optical network (AON).

A typical PON consists of an optical line terminal (OLT) and multiple ONTs; Figure 1 shows a typical PON network: an OLT located at the point of presence (POP) of the PON service provider. From OLT through an optical distribution network (ODN), the optical 
fiber reaches to fiber distribution hub (FDH) located near users' homes. In FDH, a passive optical power splitter is located which branches a single optical line from an OLT PON port to multiple optical links, each reaching a termination box (TB) just outside the user's home. From the TB, a single mode aerial cable is used to connect to an optical network terminal (ONT) located at the user's home, which provides the user with voice, Ethernet, and possibly a video interface for cable TV services. The PON technology has been constantly evolving from EPON with $1 \mathrm{Gbps}$ upstream (US) and downstream (DS) line rates to GPON with 1.2 Gbps/2.5 Gbps US/DS line rates to Next Generation PON (NGPON). The first evolution was XGPON, also termed NGPON1, with $10 \mathrm{Gbps} / 2.5 \mathrm{Gbps}$ DS/US line rates and then XGS-PON that offers symmetrical US and DS data rates of $10 \mathrm{Gbps}$. The XGS-PON uses $1577 \mathrm{~nm}$ wavelength for DS and $1270 \mathrm{~nm}$ for the US link [5] and is standardized by the ITU through its G.9807 series recommendations. The equivalent IEEE PON standard for XGPON and XGS-PON is $10 \mathrm{G}$ EPON that offers line rates of $10 \mathrm{Gbps} / 1 \mathrm{Gbps}$ for DS/US links and symmetrical 10 Gbps lines rates. The second phase of Next Generation PON is TWDM PON, also termed NGPON2, which uses WDM technology where more than one wavelength is used. All of these PON technologies are heavily deployed commercially worldwide [6]. However, the research toward further higher capacity PONs is still an active area [7]. Recently, a proposal for XGPON with $25 \mathrm{Gbps}$ line rate and field trials for time and wavelength division (TWDM) PON with 100 Gbps line rates was reported [8]; however, ITU has until now only standardized TWDM PON with a support of up to eight wavelengths ranging from 1596.34 to $1602.31 \mathrm{~nm}$ for DS and 1524 to $1544 \mathrm{~nm}$ for US in its G.989.2 series recommendations [9]. However, generally, a line rate of $40 \mathrm{Gbps} / 10 \mathrm{Gbps}$ DS/US with four wavelengths for TWDM PON is considered in PON studies.

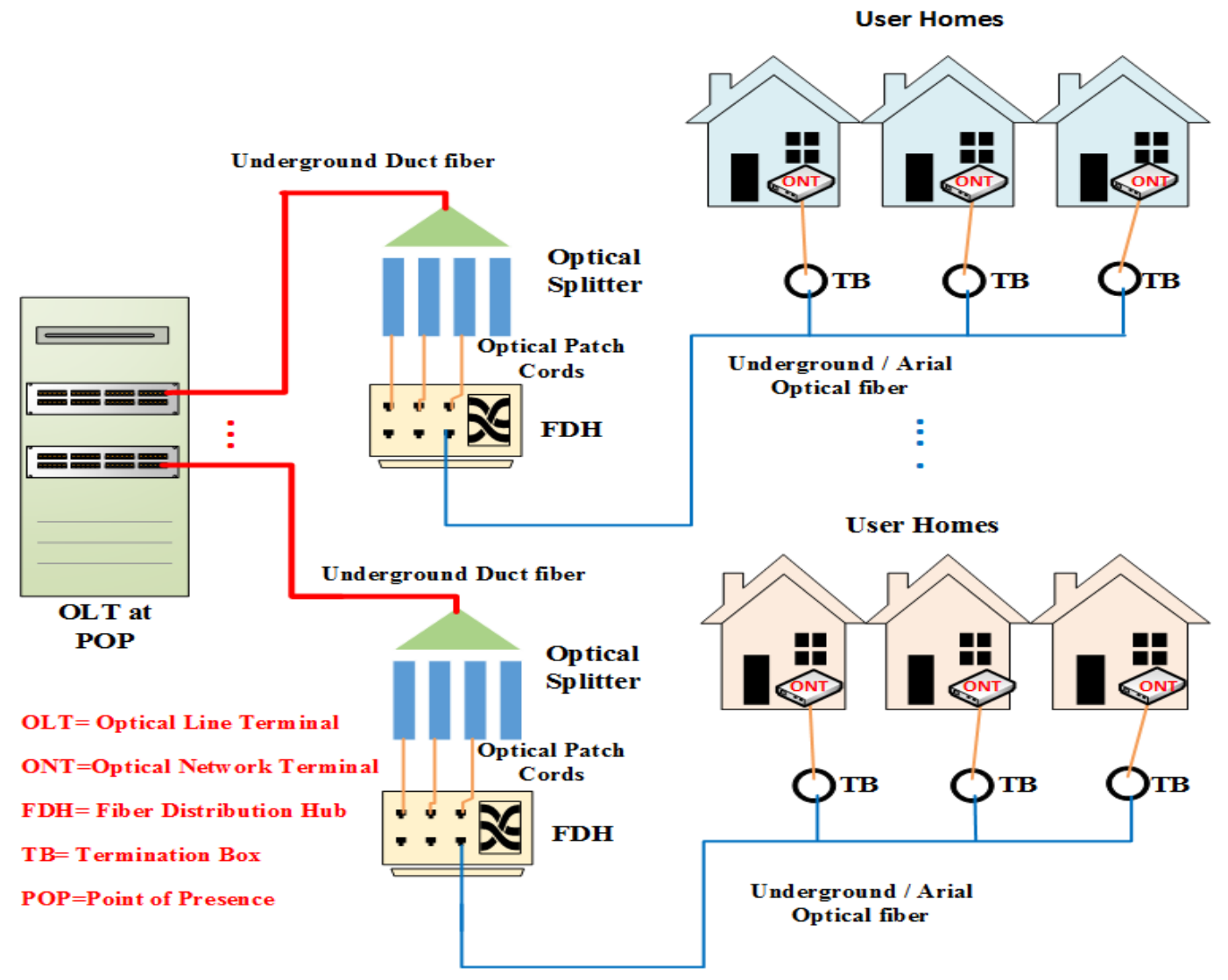

Figure 1. Typical PON deployment where the splitter is installed inside FDH.

Energy efficiency of ICT is a very important consideration and many studies have focused on this issue $[10,11]$. The PON is generally considered to be energy efficient but still the energy efficiency of the PON equipment is an important consideration as it helps to 
reduce the carbon footprint of the ICT and Telecoms sector. This is because energy efficient equipment not only reduces the electricity bill of the network operator but of the end users as well. Despite being energy efficient due to the passive nature in the access loop, the PON still suffers from higher power consumption due to the broadcast nature of the DS link. The power consumption trend is expected to increase further in NG-PON [12,13]. The main cause of this higher consumption of the PON is the continuous active state of ONTs to process the DS traffic because of its broadcast nature. Sleep mode scheme is popular for conserving energy in IP networks [14] and has also been adopted by the PON standardizing bodies such as ITU and IEEE. The ITU PON standards recommend three energy variations of sleep mode scheme for ONT energy conservation: cyclic sleep mode (CSM), cyclic doze mode (CDM), and watchful sleep mode (WSM) for its PON standards [15]. The WSM scheme is a newer scheme and is actually a unified approach to achieve the benefits of both the CSM and CDM. An ONT observing WSM periodically switches between the Doze and Asleep (AS) states during the low power state termed Watch state. During the whole Watch state, the ONT periodically checks the DS frame for the occurrence of the local wake up indication (LWI) event at the OLT that is communicated to it through the SA(OFF) message, or by setting the forced wakeup indication (FWI) bit in the BWmap field of the DS frames. Thus, the ONT is updated concerning the DS traffic condition at the OLT.

In fact, for US traffic transmission, an ONT can also quit the low power mode at any time; thus, the actual benefit of Doze state during Watch state is for the dynamic bandwidth assignment (DBA) process. Contrary to CSM, the ONTs are able to receive the queue reports from the OLT regularly during low power mode. Thus, enhanced queue reporting frequency results in better US bandwidth assignment, and hence, leads to reduced idle time for all the traffic classes when the ONT exits the Watch state. However, longer Doze periods are not very useful as the frequent queue reporting does not help much in the reduction of the US delays; rather, it results in reduced AS time for the ONT [16]. Thus, in this study, it is argued that the longer Doze state periods degrade the energy saving performance of the WSM without any notable reduction in US delays. In the current WSM standard, a symmetric approach is followed for the periodic ON and OFF of the optical receiver of the ONT to switch between the Doze and AS states, which results in reduced AS state time if the Doze period is longer. Therefore, in this work, an adaptive watchful sleep mode (AWSM) is proposed for next generation PON (NG-PON): XGPON, XGS-PON, and TWDM PON. The proposed AWSM process uses two different timers to control the Doze and AS states during the Watch state in an asymmetric manner. An adaptive approach is used to compute the Doze period during the Watch state in proportion to DS traffic load. The study results show that minimizing the Doze state period leads to prolonged AS periods resulting in enhanced energy savings without any notable increase in US and DS delays.

The remainder of the paper is organized as follows. Section 2 reviews the energy conservation schemes for PON. In Section 3, the WSM and CSM processes are described. The AWSM scheme is presented in Section 4. The simulation methodology and simulation parameters are described in Section 5. A thorough analysis and discussion of the simulation results are presented in Section 6. Finally, Section 7 concludes the study with an insight into the future research direction.

\section{Related Work}

Energy conservation schemes presented for PON can be classified as either OLTbased or ONT-based [17]. The OLT-based schemes focus on reducing power consumption of the OLT; however, there are very few such schemes: Elastic OLT [18], Master-Slave configuration [11], and OLT port sharing [19]. This is because the OLT only contributes to 7\% power consumption of PON and is the main hub of the PON, which is required to be active all the times. On the other hand, there are many ONT-based schemes because the ONT contributes to $60-70 \%$ power consumption of the PON. The prominent ONT-based energy conservation schemes presented in literature are sleep mode, adaptive link rate (ALR), ONT DS processing reduction schemes [20], ONT buffer elimination [21], and ONT physical 
hardware improvements, such as using vertical cavity lasers [22]. The DS processing reduction schemes try to reduce the ONT processing activity by improving the DS frame structure. The scheme in [23] also reduces the dynamic power consumption of the ONTs, but it requires architectural changes in the hardware of the ONT. The study in [20] tries to minimize the processing energy wastage with the help of a novel frame structure for GPON. However, the study results have not been verified at hardware level. The ALR scheme also reduces the dynamic power consumption of the ONT by adapting to lower line rates when traffic load is less than a predefined threshold. However, the ALR scheme requires presence of multirate transceivers at the OLT and the ONTs. The pure medium access layer (MAC)-based schemes that do not require any physical changes in the ONT are the sleep mode schemes: cyclic sleep mode (CSM)) [24], sleep and periodic wake up (SPW) [25-27], cyclic doze mode (CDM) [28,29], and watchful sleep mode (WSM) [30,31]. The reader is referred to [17] for a comprehensive recent review of the PON energy conservation schemes.

The most studied and common energy conservation scheme for PON is CSM $[32,33]$. In CSM, most of the existing studies have neglected the role of the DWBA or DBA process, which plays a key role in the optimization of the CSM process. Only a few studies have addressed this problem and present an integrated scheme such as in [34-36]. The study in [37] presents a sleep and doze control merging scheme using the DBA process. The VSCEL laser transmitter is used to reduce initialization time of the ONTs. Based on the ONT idle time length, the ONT is either switched to Asleep state or Doze state. However, it is not clear in this study how the authors compute the ONT idle time; it is a future parameter and can only be predicted, but no prediction scheme was used by the authors. Another similar scheme is presented in [38]. Another similar proposal in [35,36] presents a sleep mode aware (SMA) algorithm, which is actually based on the IPACT scheme to support CSM process. The main idea is to keep ONT in sleep mode and only active in the assigned time slot. Both DS and US traffic are buffered for the ONT and its Active state time is computed according to the queued traffic. The maximum of the DS or US transmission time is chosen as the Active state time for the ONT. The study in [39] also presents hybrid doze and sleep mode assignments while keeping in view US and DS queues for an EPON-based architecture. The study in [33] achieves energy efficiency by switching OLT transceivers to lower rate or turning them off in a SDN architecture, but it requires SDN-compliant OLT architecture.

Although ONT sleep mode is a widely studied [40] scheme for PON, there are, however, only a few studies on WSM in the current literature. Most of the existing reported works for WSM have studied its delay and energy saving performance by developing an analytical model for the WSM process [30,31,41,42]. The study in [41] suggests that $20 \mathrm{~ms}$ is an optimal sleep period for WSM and it can provide up to 70\% energy savings with up to $35 \mathrm{~ms}$ delay when there is no traffic arrival. The extended work by the same authors in [31] further investigates the performance of WSM for different traffic patterns: liner, exponential, and constant. The study results show that the exponential traffic pattern severely degrades the energy-saving performance of WSM and leads to higher delays at high traffic load. However, these studies consider only a single ONT and do not differentiate between the US and DS traffic; thus, their modeling is not realistic. A more realistic modeling is presented in [30], in which 16 ONTs are considered and a static bandwidth assignment mechanism is also assumed. The study compares the performance of WSM with CSM and argues that the Watch state time period must be significantly greater than the AS period of CSM for significant energy savings. In their extended work [40], the authors have performed the same comparison in an OMNET++ simulation environment and have shown that WSM can achieve 20\% higher energy savings compared to CSM. This comparison is not realistic as they have used an AS period of $10 \mathrm{~ms}$ for CSM and $1 \mathrm{~s}$ for WSM, which means the low power state of WSM will be always higher for WSM. If the low power state period of WSM and CSM is kept equal as in [43,44], then the power consumption of the WSM will be higher than CSM; thus, CSM will be comparatively more energy efficient. However, WSM can offer comparatively lower state transition delays due to periodic Doze state during the Watch state. Another effort in [41] uses a modeling approach using discrete-time 
Markov chain to show WSM outperforms existing energy saving schemes, i.e., CSM and $\mathrm{CDM}$ in terms of power consumption and state transition delays. However, the modeling is not properly presented and it is also not clear that the authors used CSM or CDM for comparison with WSM. Another recent study [42] tried to reduce the power consumption of an ONT by merging the WatchAware (WA) and ActiveHeld (AH) states into a single Active state, which is actually not compliant with the ITU WSM standard. They minimize the ONT stay in Active state by quickly exiting it on traffic arrival; thus, we call this scheme QWSM. This approach will theoretically minimize the ONT stay in Active state and will reduce its power consumption, but this is impractical as the ONT sojourn in Active state should be at least greater than the service interval (SI) period of the DBA scheme so that ONT can send it queue reports to OLT and receive the DBA grants. Moreover, to the best of our knowledge, a true comparison of WSM and CSM schemes in the presence of a DBA scheme has not yet been reported.

Therefore, in this work the WSM scheme is thoroughly studied in terms of the ONTs delay, jitter, and energy savings performance against different traffic loads. The performance of the WSM scheme is also compared with the CSM scheme. Specifically, the ON time of the optical receiver $\left(T_{O N}\right)$ of the ONT is minimized and chosen in an adaptive manner according to the current DS traffic arriving at the OLT for the ONT. Moreover, to the best of our knowledge, a true comparison of WSM and CSM schemes in the presence of a DBA scheme has not yet been reported. Therefore, in this work a DBA process is also considered that is used to distribute the US bandwidth to all the type 1 (T1), type 2 (T2), type 3 (T3), and type 4 (T4) traffic classes, according to their bandwidth demand.

\section{Watchful and Cyclic Sleep Processes}

The WSM process is an integration of CSM and CDM processes in which the ONT continuously switches between the Doze and AS states instead of continuously being only in AS state as in the CSM scheme. Figures 2-4 show the state transition process for the WSM, AWSM, and CSM schemes. Where $T_{A F}, T_{W A} T_{A S}, T_{R x_{-} \text {Init }}, T_{\text {Init }}$, and $T_{\text {Doze }}$ are the ONT sojourn in AF, WatchAware (WA), AS, Doze to Active transition state, and transceiver initialization state, respectively, and the $P_{A F}, P_{W A}, P_{D o z e}$, and $P_{A S}$ are the power levels of the AF, WA, Doze, and AS states, respectively. The main difference between the watchful and CSM processes lies in the AS state. In the CSM the ONT keeps the optical transmitter and receiver OFF during the AS state while in the WSM process it keeps turning its optical receiver ON and OFF. The detailed state transition process of WSM is shown in Figure 4. Similar to CSM, in WSM the ONT also stays in AH state unless allowed by OLT to enter the Watch state. An ONT keeps on trying to enter ActiveFree (AF) state after every $T_{\text {Hold }}$ time. The OLT permission for an ONT to use the WSM mode is granted by sending a Sleep_Allow (ON) PLOAM message in the DS frame. When an ONT receives this message, it sets its local SA (ON) flag and transitions to AF state after the expiry of the $T_{\text {Hold }}$ timer. This timer is used to keep count of the sojourn in AH state. Thereafter, if the US and DS traffic queues are empty and thus the respective LWI events, $L W I_{O N T}$ and $L W I_{O L T}$, are not triggered, then the ONT transitions to WA state for a time period of $T_{W A}$ and then the Watch state for a period of $T_{\text {Watch }}$. Unlike the AS state in CSM, here the ONT periodically keeps on turning ON and OFF its optical receiver (RX); however, the optical transmitter is kept OFF. By turning on the RX, the ONT actually switches to Doze mode. During the Watch state, the ONT continuously switches between Doze and AS states. This switching from AS state to Doze state requires an initialization time $T_{R x_{-} \text {Init }}$ to turn on the ONT RX. 


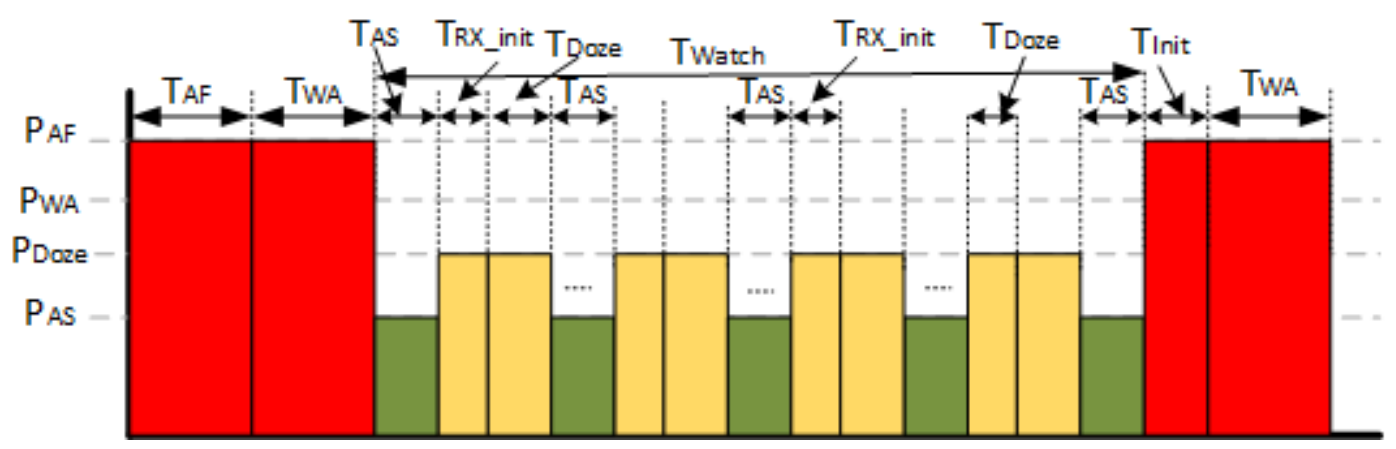

Figure 2. ONT state transition process of standard watchful sleep mode showing power levels and time durations of each state.

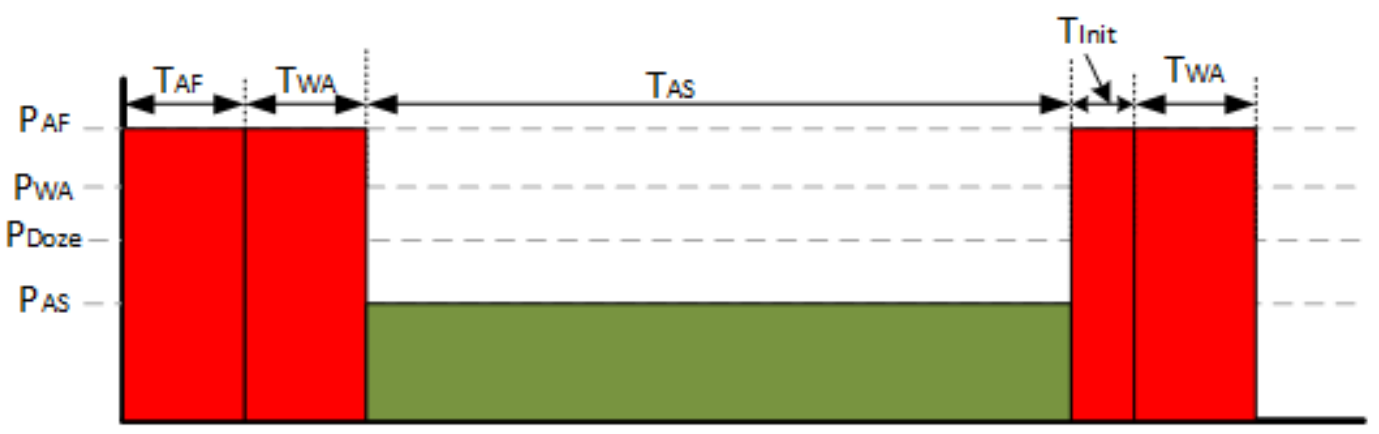

Figure 3. ONT state transition process of cyclic sleep mode showing power levels and time durations of each state.

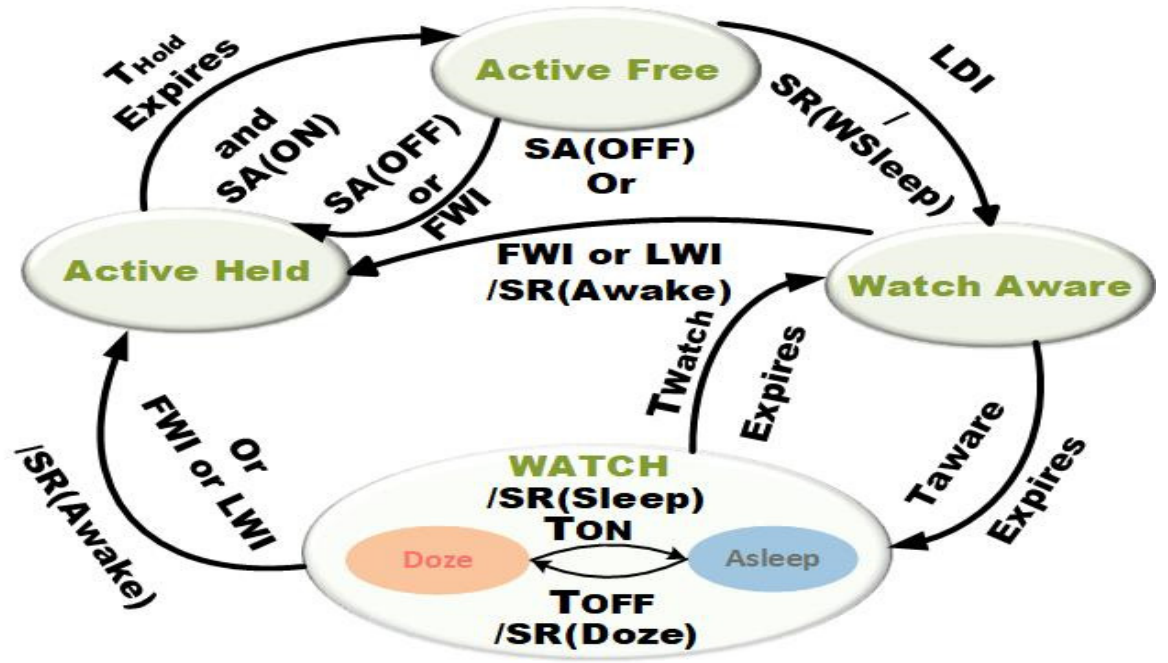

Figure 4. ONT state transition process for WSM scheme showing the transition conditions for each state.

\section{Adaptive Watchful Sleep Mode (AWSM)}

\subsection{System Description}

The AWSM state transitions process for the ONT is quite similar to standard WSM process and only differs in the Watch state, as shown in Figure 5a,b. In standard WSM process the ON and OFF periods may have different lengths and require two separate timers $T_{O N}$ and $T_{O F F}$. However, the values of these timers are not optimized to maximize the ONT energy savings. During the Doze state the ONT receives the DS traffic, but only parses the BWmap field to know about its US time slot allocations and the status of the FWI flag. In our initial study [16] it was shown that the asymmetrical selection of $T_{O N}$ and $T_{\text {OFF }}$ leads to higher energy savings (ES) and lower US delays; however, no mechanism for 
the computation of $T_{O N}$ was given. In this study, the idea of an intelligent PON system as earlier presented in [45] is used for the computation of the $T_{O N}$ using Equation (1), where $\beta_{D S}$ is the DS traffic arrival rate and $\mathcal{R}_{D S}$ is the DS Line rate of the PON. The US traffic is not considered for this calculation because ONT cannot transmit during the Watch state and US traffic demand cannot be sent to OLT. Half of round trip time (RTT) time is also added because the traffic arrival time from OLT to ONT will take this time and ONT should be able to receive the US frame to check for a possible FWI event set by OLT. The ON frequency $F_{O N}$ of the $T_{O N}$ timer is also increased asymmetrically in accordance to the DS traffic arrival by using Equation (2), where $\zeta$ is the load step size that acts as an acceleration factor for the increase of $F_{O N}$ with increasing $F_{O N}$. Its value is chosen in the range 0.1 to 0.2 . The minimum value of $F_{O N}$ is 1 and is always rounded up. The value of $T_{O F F}$ timer is computed by Equation (3) and depends upon the choice of $T_{\text {watch }}, T_{O N}$, and $F_{O N}$. The $T_{\text {watch }}$ is the total duration of the Watch state in which multiple instances of $T_{O N}$ and $T_{O F F}$ may occur with a frequency of $F_{O N}$. The AWSM process is highly customizable as it can be easily converted to WSM, CDM, or CSM schemes by setting $T_{O N}=T_{O F F}, T_{O N}=T_{\text {watch }}$, $T_{O F F}=0$, and $T_{O F F}=T_{\text {watch }}$ and $T_{O N}=0$, respectively.

$$
\begin{gathered}
T_{O N}=T_{R x_{\text {Init }}}+\frac{\beta_{D S} * 125}{\left(10^{6}\right)\left(\mathcal{R}_{D S}\right)}+\frac{R T T}{2} \\
F_{O N}=\max \left(\frac{\beta_{D S}}{\zeta * \mathcal{R}_{D S}}, 1\right) \\
T_{O F F}=\frac{T_{\text {watch }}-\left(T_{O N}\right)\left(F_{O N}\right)}{F_{O N}}
\end{gathered}
$$

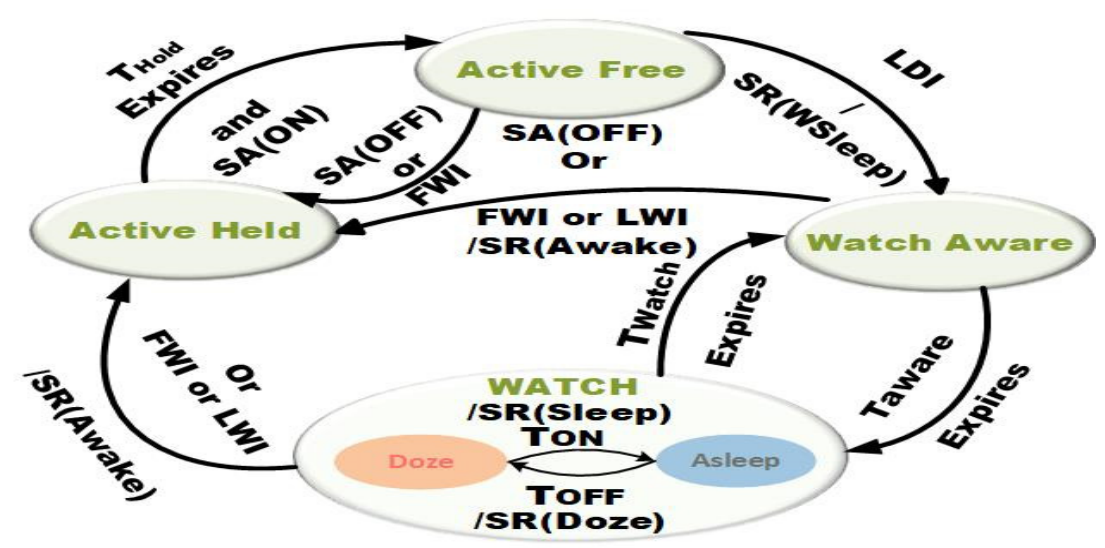

(a)

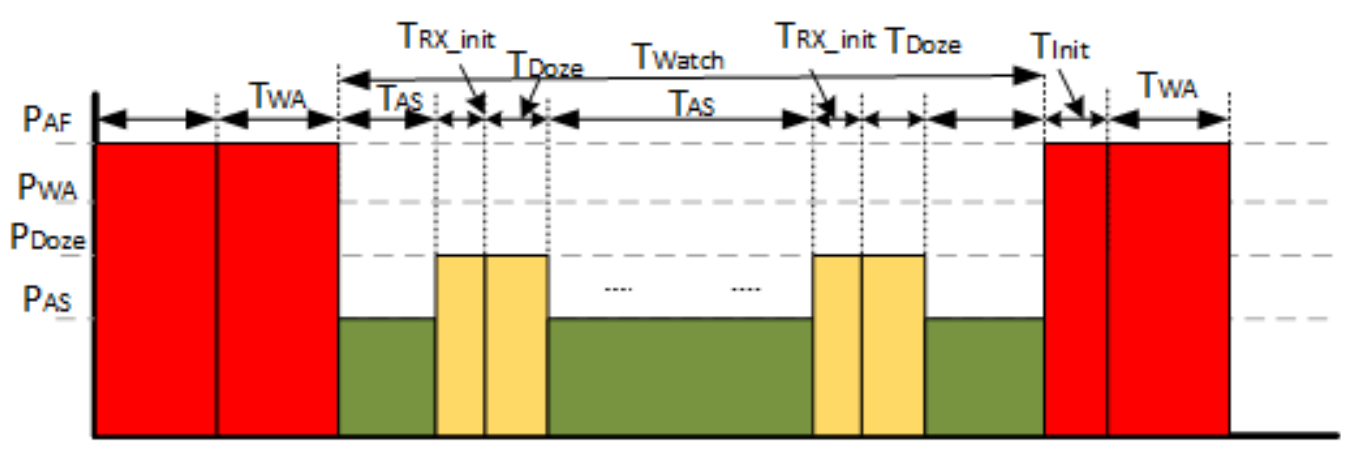

(b)

Figure 5. Diagram showing (a) ONT state transitions for AWSM scheme. (b) Power levels and state sojourn of the ONT in each state for AWSM scheme. 
$T_{\text {Low_Power }}$ represents the ONT sojourn in either of the AS or Watch state during its low power mode. In the case of CSM simply the $T_{\text {Low_Power }}=T_{A S}$, but for the WSM process the $T_{\text {Low_Power }}=\mathrm{T}_{\text {Watch }}=T_{\text {Doze }}+T_{A S}+T_{R X_{-} \text {init }}$. Thus, the ES per ONT for CSM and WSM schemes can be expressed by Equations (4) and (5), where $T_{\text {Sim }}$ is the total simulation time, $P_{A S}, P_{\text {Doze }}$, and $P_{\text {Active }}$ are the power consumption of the ONT AS state, Doze state, and Active state, i.e., either of the AF, AH, and SLA or WA states. Similarly, $T_{\text {Active }}$ is the ONT sojourn in any of the active states such as WA, SLA, Active Held (AH), or Active Free (AF) states, as these are all states that have the same power level, $P_{\text {Active }}$ due to ONT transceiver being in the ONT state. Since $P_{\text {Doze }}>P_{\text {Sleep }}$, therefore, the ES performance of WSM is critically dependent on the $T_{O N}$ and $T_{O F F}$ timers that periodically control the switching between the Doze and AS states. To the best of our knowledge, this impact has not been studied in any of the earlier WSM studies. Therefore, it has been addressed in this study along with a comparison to CSM process in terms of US latency and ONT energy savings. However, it can be fairly concluded from Equations (4) and (5) that for the WSM process to have the same ES as that of CSM, the necessary condition is $E S_{W S M}=E S_{C S M}$ for the same $T_{\text {Sim }}$. This can only happen when $T_{D o z e}=0$ and $T_{R x_{-} \text {Init }}=0$, which will actually convert the WSM process to CSM. Therefore, by no means is it possible that $E S_{W S M}>E S_{C S M}$ for the same $T_{\text {Low_Power }}$ and $T_{S i m}$ periods. However, the $E S_{W S M}$ can be maximized and made close to $E S_{C S M}$ by minimizing the $T_{O N}$ and $T_{R x_{-} \text {Init }}$. Since $T_{R x_{-} \text {Init }}$ is a hardware parameter which is fixed for a particular ONT architecture, then the only possibility is to minimize the $T_{O N}$ theoretically to one XGPON frame duration of $125 \mu$ s. However, in addition to US traffic transmission, an ONT also has to send its queue reports to OLT once every service interval (SI). Therefore, to ensure smooth working of the dynamic bandwidth assignment (DBA) process, it is necessary to have $T_{O N}$ higher than $T_{S I}$ plus the time required to clear the queued traffic at the ONT.

$$
\begin{array}{r}
E S_{C S M}(\%)=\left(1-\left(\frac{T_{\text {Low_Power }} * P_{\text {AS }}+T_{\text {Active }} * P_{\text {Active }}+T_{\text {Init }} * P_{\text {Active }}}{T_{\text {Sim }} * P_{\text {Active }}}\right)\right) * 100 \\
E S_{W S M}(\%)=\left(1-\left(\frac{T_{O N} * P_{\text {Doze }}+T_{A S} * P_{\text {AS }}+T_{\text {Active }} * P_{\text {Active }}+T_{R x_{-} \text {Init }} * P_{\text {Doze }}+T_{\text {Init }} * P_{\text {Active }}}{T_{\text {Sim }} * P_{\text {Active }}}\right)\right) * 100
\end{array}
$$

\subsection{Adaptive Sleep Control Algorithm}

The AWSM process improves the standard WSM process by employing the timer $T_{O N}$ and three flag variables: SleepAlert, ShutDownRx Flag, and WatchAlert inside the WSM process that are being controlled through timer $T_{\text {Watch }}$. The detailed process is shown in the Algorithm 1, which is executed in every DS cycle at the OLT. The variables AS_Time, RX_Time, Init_Start_RX, and Init_Time are used to measure the ONT sojourn in AS state, Doze state, AS to Doze state, and AS to Active state transition during the whole simulation time. The ONT Mode values range from 1 to 4 representing the ONT AH, AF, SLA, and AS states, respectively. The ShutDownRxFlag controls the ONT optical receiver. The process triggers whenever the ONT transitions from the SLA state to Watch state indicated by the SleepAwareFlag $=0$ condition. The suitable traffic condition of the ONT to enter into AWSM cycle, which consists of the WA and Watch state, is indicated by the LWI $I_{O N T}$ that is controlled based on the queue length of the T1 traffic, as described in previous section, through the sleep buffer approach earlier presented in [46]. In lines 1-3, the $L W I_{O N T}$ event is monitored and Watchful sleep process is abandoned if traffic is higher than the predefined threshold; otherwise, the process is allowed by setting the SleepAlert and WatchAlert flags in lines 4 to 6 . In lines 8-27, Watchful sleep process for ONT is started with both transmitter and receiver turned off and related state timers; Timer $_{\text {Watch }}$ and $\operatorname{Timer}_{\mathrm{TRx}}$ are loaded to $T_{w}$ and $T_{\text {OFF }}$ values, respectively. The $T_{\text {OFF }}$ time is computed by Equation (3). However, when

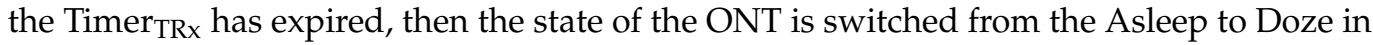
lines 15 to 19 with a certain delay to emulate the receiver initialization time in lines 28 to 33 . 
Finally lines 34 to 41 handle the ending of the Watchful sleep state at the expiration of the Timer $_{\text {Watch }}$ at the end of time $T_{w}$.

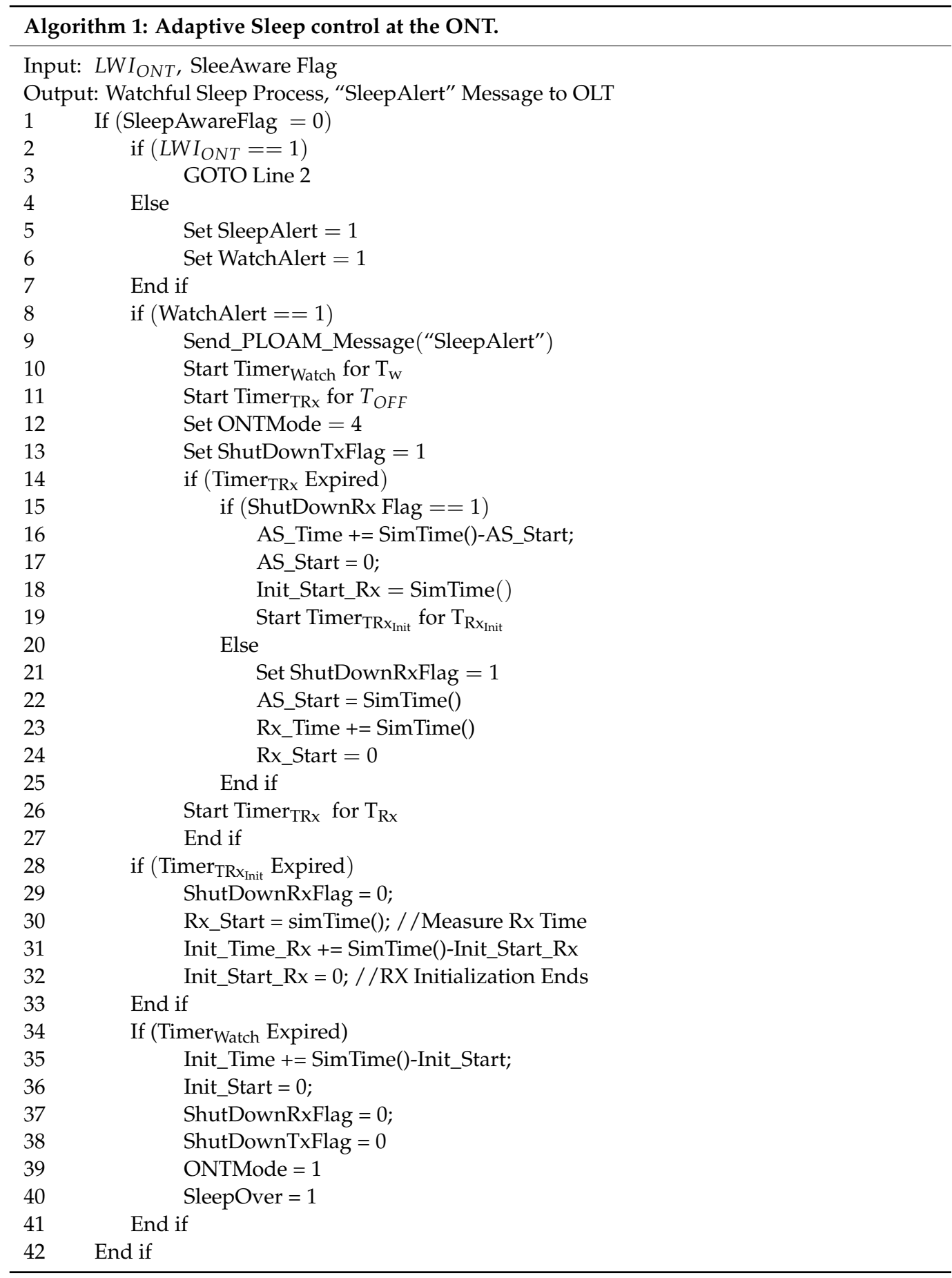

\section{Performance Evaluation}

To study and compare the performance of AWSM with other schemes proposed in literature, an XGPON network was designed in OMNET++ environment comprising 1 OLT connected with 32 ONTs through branched fibers similar to other studies [23,47]. It was assumed that all the ONTs were perfectly ranged and appear to OLT as being located at the maximum distance of $20 \mathrm{~km}$. For simplicity, only one host and one user was configured per ONT. One instance of the traffic generator node was created for each ONT. According to the desired traffic load selected at runtime, the generator first computes the mean arrival rate ( $\beta$ ) per ONT in frames per second using Equation (6), where the Link_Rate is the capacity in 
bytes per second of the US or DS links which for XGPON is 1,244,240,000 bytes per second and $311,040,000$ bytes per second, respectively. The interarrival time (I.I.T) is computed in seconds per frame by Equation (7) using exponential distribution, where $\mathcal{F}_{\text {avg }}$ is the average frame size of the generated traffic frames and is measured in bytes per frame. The Traffic_Load is the ratio of total traffic bytes sent per second by all the ONTs and the Link_Rate. For DS, it varies from 0.01 to 0.88 corresponding to a traffic arrival rate of $3 \mathrm{Mbps}$ to $275 \mathrm{Mbps}$ per ONT.

The US load is set to one fourth of DS in proportion to its line rate compared to DS as in [39]. The traffic frames are generated using a triangular distribution with an average frame size of 435 bytes $[48,49]$ using the algorithm shown in Figure 6 and the help of a flowchart. The duration of each simulation varies as it depends upon the convergence time of $\beta_{D S}$. The simulation is terminated when the mean of the observed values of $\beta_{D S}$ converges to a value within $95 \%$ of its confidence interval.

$$
\begin{gathered}
\beta=\frac{\text { Traffic_Load } * \text { Link_Rate }}{j * \mathcal{F}_{\text {avg }}} \\
\text { I.I.T }=\text { Exponential }\left(\frac{1}{\beta}\right)
\end{gathered}
$$

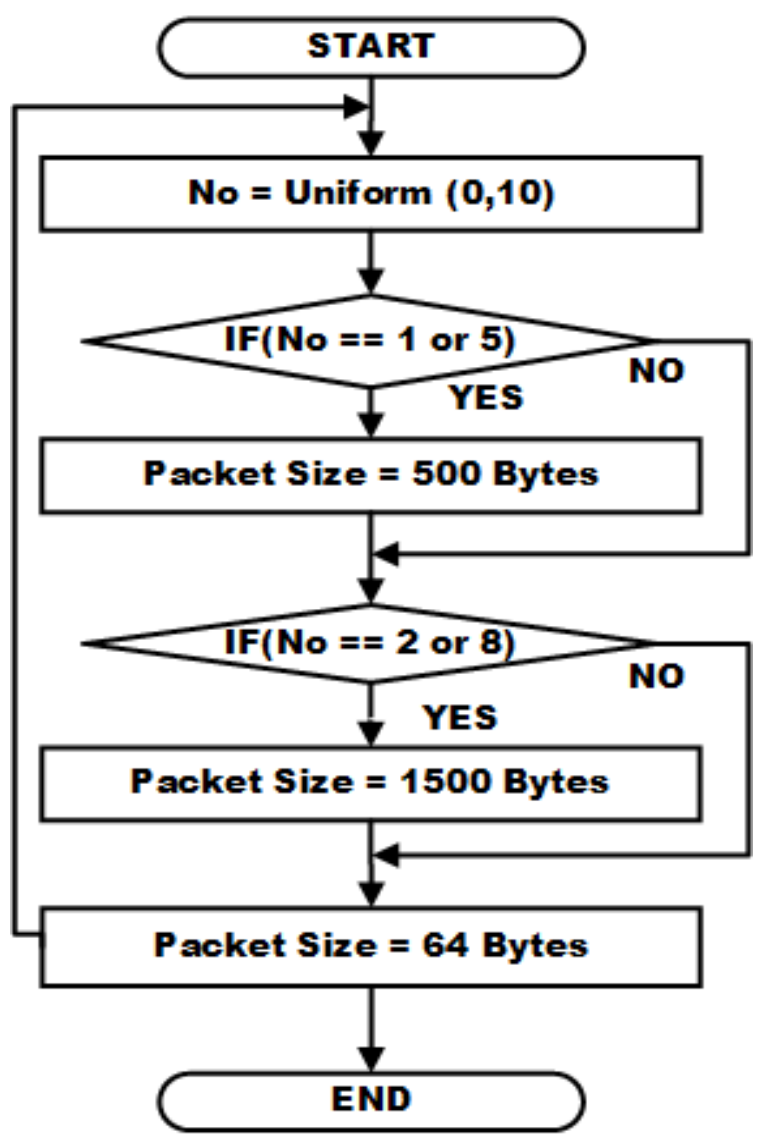

Figure 6. Frame size selection process according to triangular distribution.

The AWSM scheme is compared with the WSM [39] and QWSM [41] schemes. However, the QWSM scheme completely eliminates the WA state, which is actually not possible when a DBA scheme is being used, as ONT requires an active state time to send queue reports to the OLT. Therefore, for QWSM the SA time is set to a minimum possible value. For the US bandwidth management, the EBU DBA scheme presented in [49] is used. The line rate between the user and ONT is set to $100 \mathrm{Mbps}$ with a reserved bandwidth of $10 \%$ for $\mathrm{T} 1,45 \% \mathrm{~T} 2$, and 45\% T3 traffic. The T4 traffic is assigned $90 \mathrm{Mbps}$ on best effort basis. 
A service interval (SI) of 10 is used and respective byte counters for $\mathrm{T} 1$ to $\mathrm{T} 4$ traffic; $A B m i n_{1}$, $A B$ min $_{2}, A B$ min $_{3}, A B s u r_{3}$, and $A B s_{4} r_{4}$ are charged to their respective values according to the configured bandwidth. The AWSM scheme is also compared with the CSM scheme with the sleep and DBA parameters shown in Table 1, similar to the study in [38] with transmitter initialization time $T_{T X \_ \text {init }}$ adapted from [34].

Table 1. Additional simulation parameters.

\begin{tabular}{|c|c|}
\hline Parameter & Values \\
\hline$T_{A S}$ & $1 \mathrm{~s}$ \\
\hline$T_{R X \text { init }}$ & $2 \mathrm{~ms}$ \\
\hline$T_{T X}$ init & $330 \mathrm{~ns}$ \\
\hline$T_{O N} / T_{O F F}$ & Watch state ON/OFF values computed using Equations (1) and (3). \\
\hline$T_{S A}$ & $2 \mathrm{~ms}$ \\
\hline$T_{\text {Init }}$ & $2.33 \mathrm{~ms}$ \\
\hline$T_{\text {Hold }}$ & $0.5 \mathrm{~ms}$ \\
\hline$T_{E R I}$ & $\geq\left(T_{A S}+T_{\text {init }}+S I+\mathrm{RTT}\right)=1.05 \mathrm{~s}$ \\
\hline$T_{A L E R T E D}$ & $\geq\left(T_{A S}+T_{S L A}+T_{\text {init }}\right)=1.08 \mathrm{~ms}$ \\
\hline$P_{A S}$ & $5 \%$ \\
\hline$P_{\text {Doze }}$ & $40 \%$ \\
\hline$P_{W A}$ & $100 \%$ \\
\hline$P_{\text {Active }}$ & $100 \%$ \\
\hline$A B$ min $_{1}$ & $=315$ bytes with $S I=10$ (10 Mbps Bandwidth) \\
\hline$A B$ min $_{2}$ & $=7030$ bytes with $S I=10$ (45 Mbps Bandwidth) \\
\hline $\mathrm{ABmin}_{3}$ & $=3515$ bytes with $S I=10$ ( $22.5 \mathrm{Mbps}$ Bandwidth) \\
\hline $\mathrm{ABsur}_{3}$ & $=3515$ bytes with $S I=10$ ( $22.5 \mathrm{Mbps}$ Bandwidth) \\
\hline $\mathrm{ABsur}_{4}$ & $=1460$ bytes with $S I=10$ (90 Mbps Bandwidth) \\
\hline
\end{tabular}

\section{Results and Discussion}

The performance of the AWSM, QWSM, WSM, and CSM schemes is compared in terms of ONT average AS state time; Doze state time; ES per ONT, US, and DS delays; and delay variance. The recorded results from the simulation are shown in Figures 7-13.

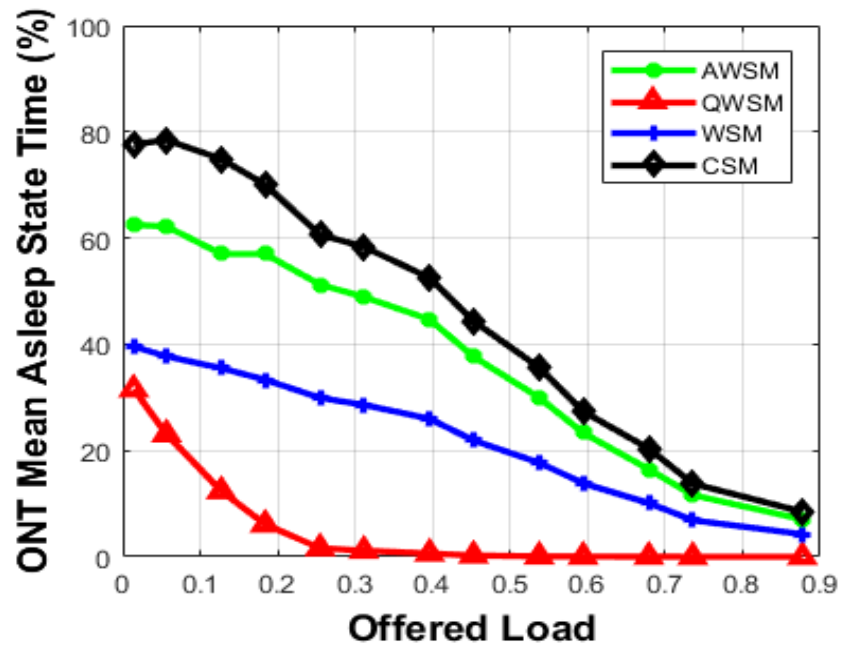

(a)

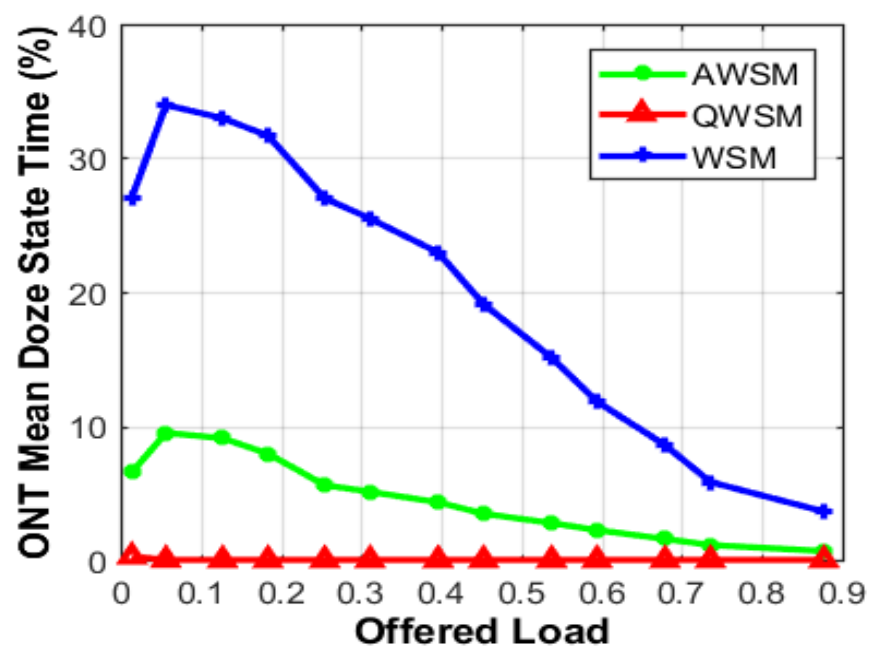

(b)

Figure 7. (a) ONT AS time in for all schemes in percent of total simulation time. (b) ONT Doze state time in percent of total simulation time. 


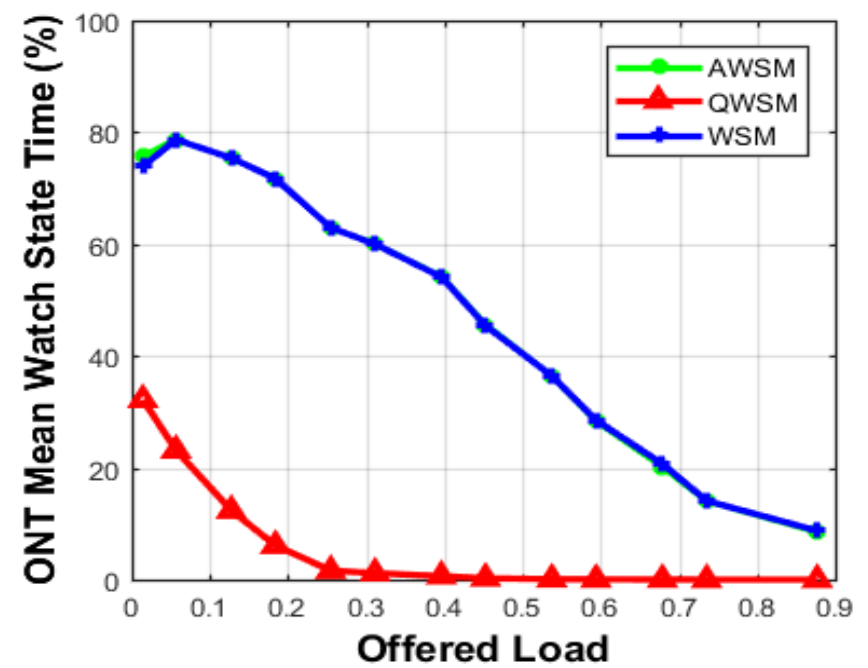

(a)

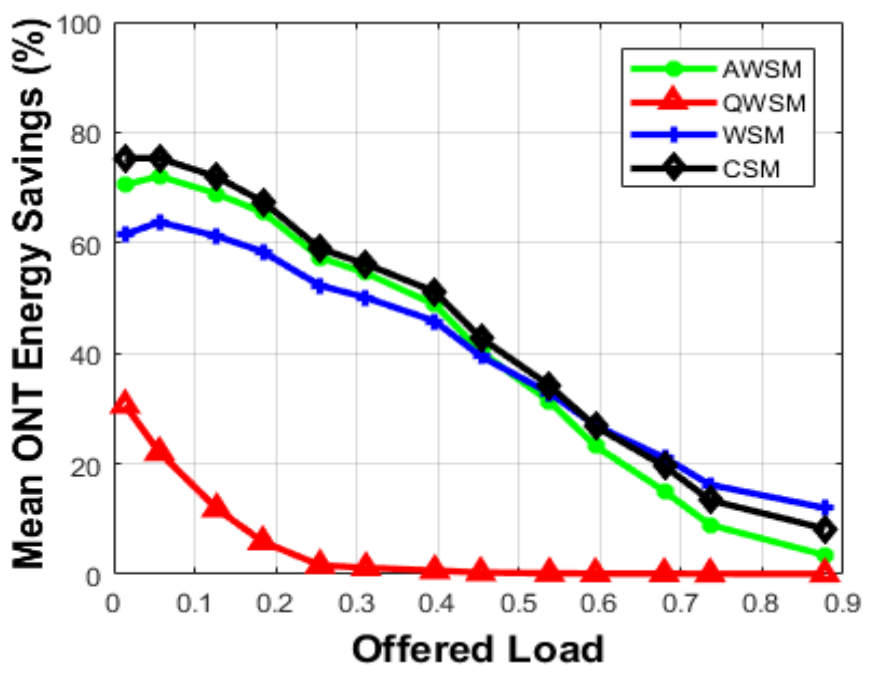

(b)

Figure 8. (a) ONT mean Watch state time. (b) ONT Mean Energy savings.

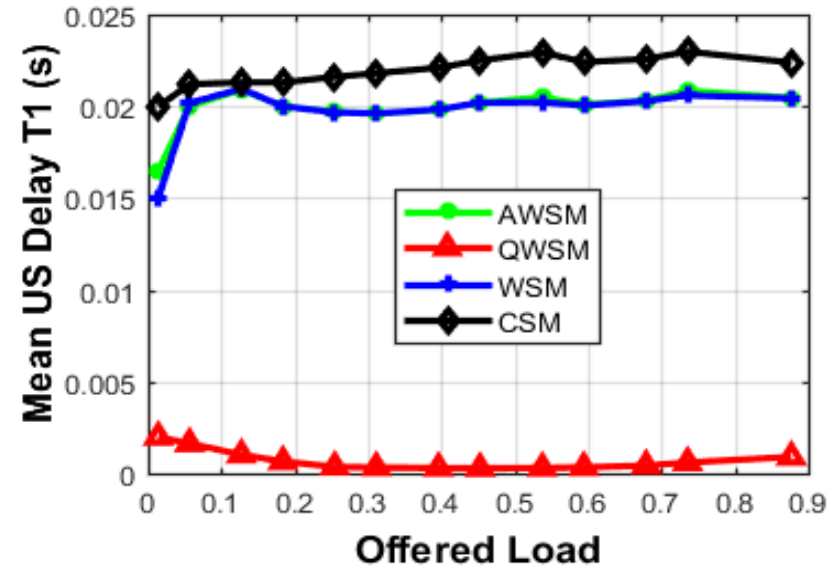

(a)

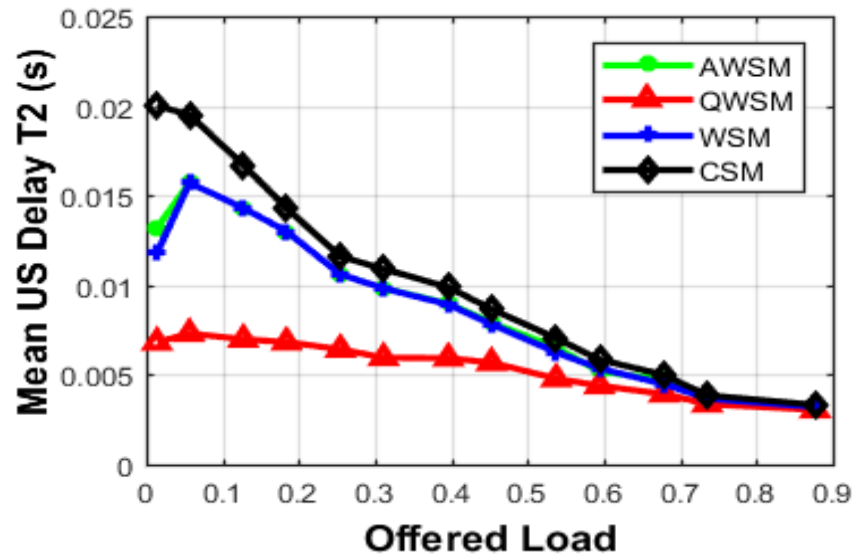

(b)

Figure 9. Mean US delay of ONT for (a) T1 traffic class and (b) T2 traffic class.

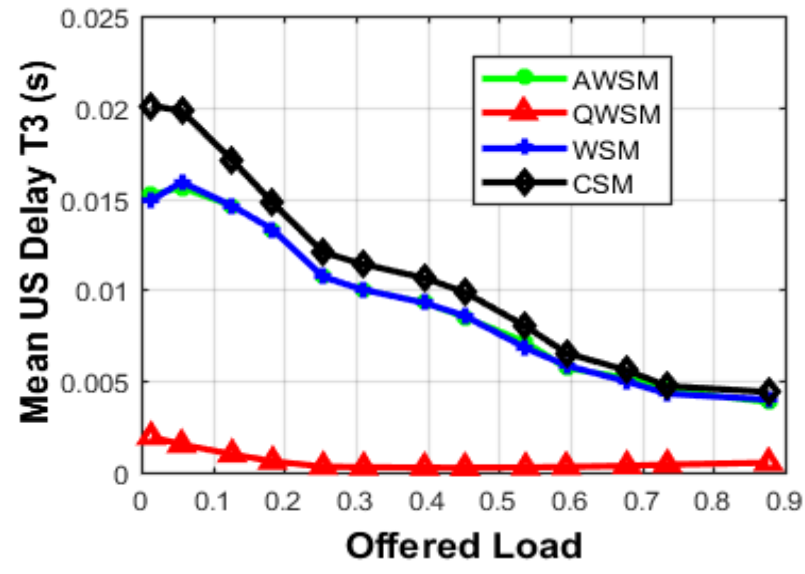

(a)

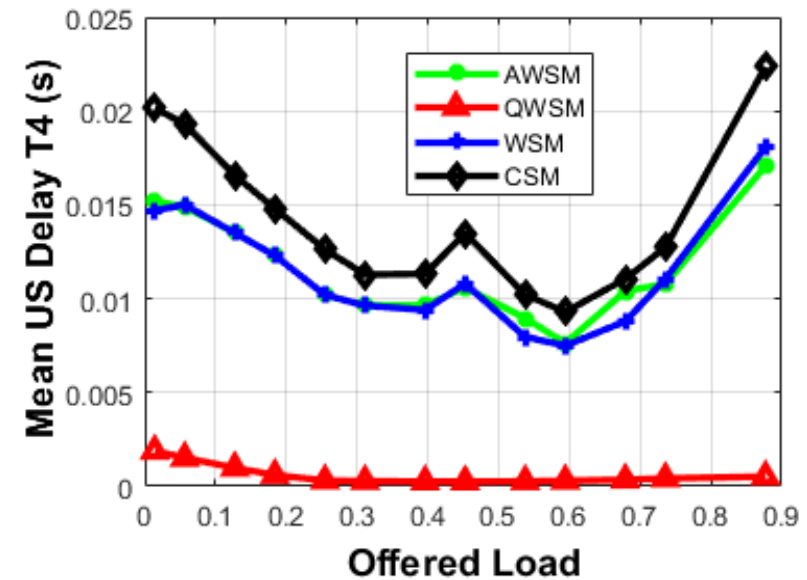

(b)

Figure 10. Mean US delay variance of (a) T3 traffic class and (b) T4 traffic class. 


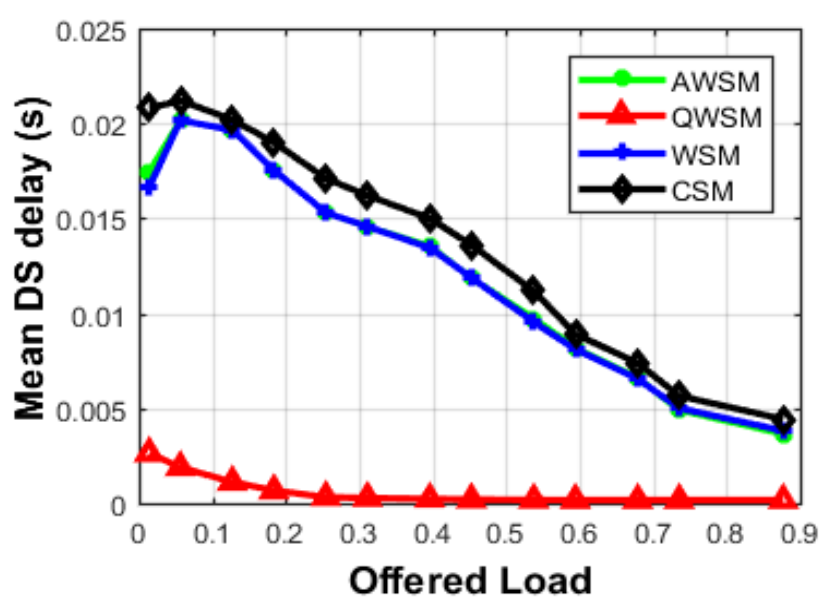

(a)

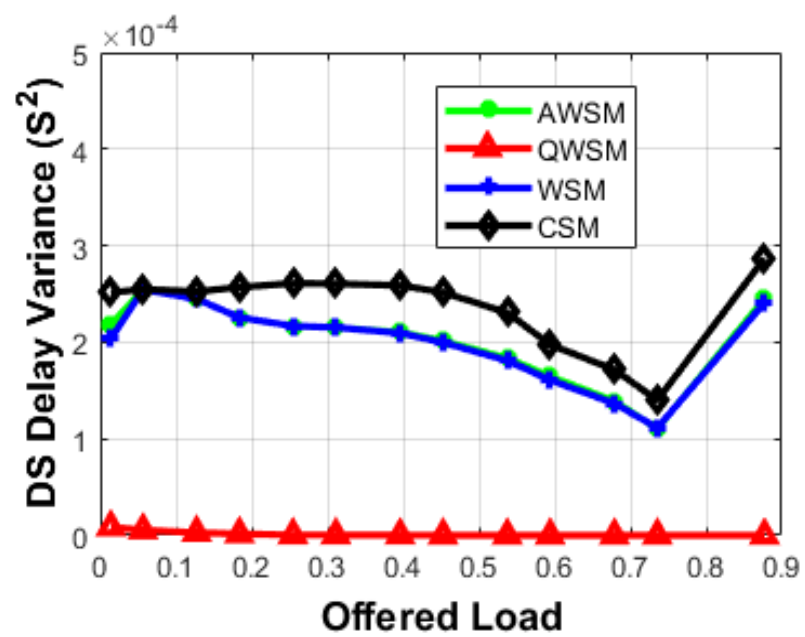

(b)

Figure 11. (a) Mean DS delay and (b) mean DS delay variance.

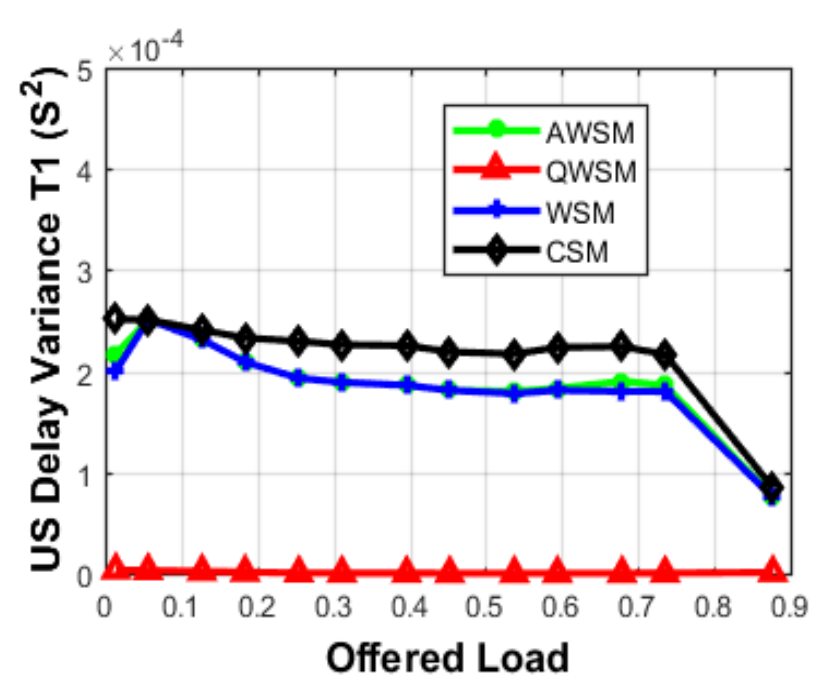

(a)

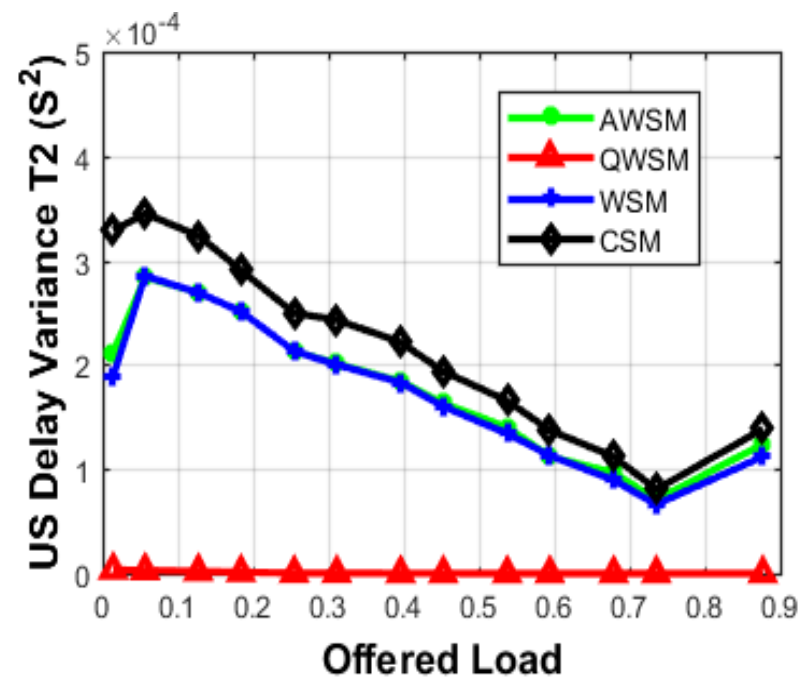

(b)

Figure 12. Mean US delay variance of (a) T1 traffic class and (b) T2 traffic class.

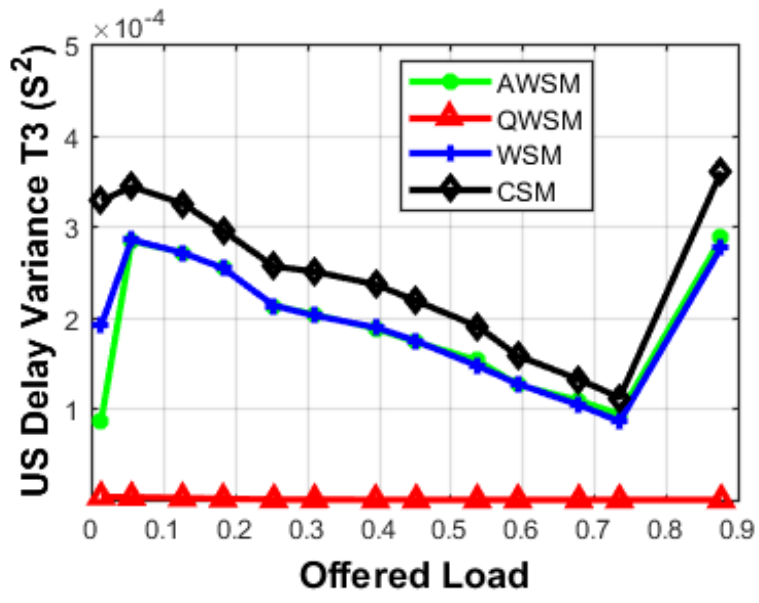

(a)

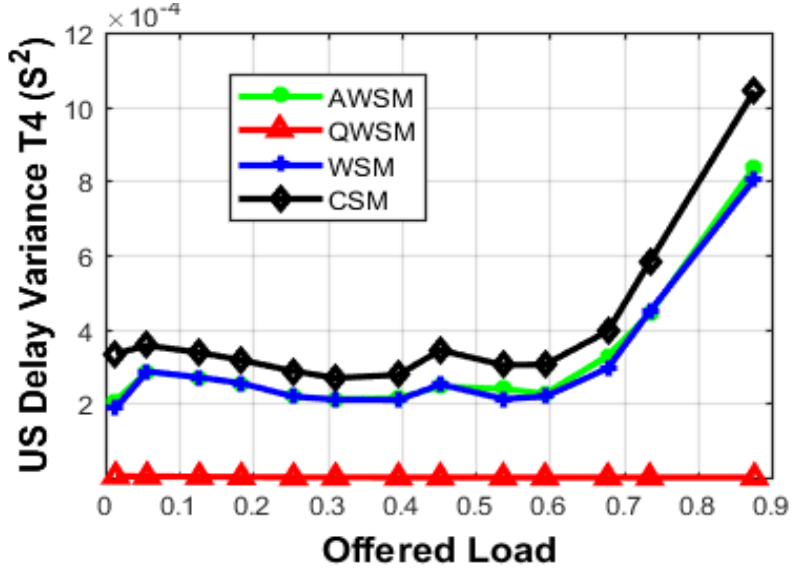

(b)

Figure 13. Mean US delay variance of (a) T3 traffic class and (b) T4 traffic class. 
As also described in Section 4, the watchful approach can never result in higher ONTs sleep time compared to the CSM scheme if the duration of the ONT low power mode is the same. This is evident from the results shown in Figure 7a. However, the AWSM scheme results in only a maximum of $15 \%$ lesser AS state time for an ONT compared to CSM for at least traffic load of 0.01 . However, its performance is much improved compared to the standard WSM process and it results in up to $24 \%$ higher AS state time for the ONTs. This is due to minimization of the $T_{O N}$ period due to an adaptive approach during the Watch state. The QWSM scheme shows least AS state time due to quickly exiting Watch state on traffic arrival, as described in Section 2.

The asymmetric selection of $T_{O N}$ in an adaptive manner also results in reduced average Doze state time per ONT for the AWSM scheme compared to WSM, as evident in Figure 7b. The ONTs using QWSM show almost zero Doze state time as they quit Watch state while being in AS state before entering Doze state on even a single frame arrival.

However, the total recorded Watch state time for AWSM and WSM remains the same as shown in Figure $8 \mathrm{a}$, as they only differ in the choice of $T_{O N}$ while total Watch state period remains almost the same. However, the QWSM scheme shows the least Watch state time due the same reasons discussed above.

Since the ONT AS state time is proportional to the length of the ONT sojourn in AS state time, referring to Equations (3) and (4), therefore, the ONT ES follow almost the same trend as of the ONT AS state time. Thus, again the AWSM scheme shows the highest ES after the CSM scheme, as shown in Figure 8b. The CSM scheme shows highest ES of 75.35\%, followed by AWSM with 70.54\%, and WSM with 61.53\% and 30.69\% for the QWSM scheme at very low traffic load of 0.01 . The ES\% results of AWSM are up to $9 \%$ higher than WSM and only $4 \%$ less than CSM scheme. At high traffic loads around 0.5 to 0.6 , all schemes, except QWSM, show almost equal savings in the range of 23\% to $28 \%$ because of higher Active state time and reduced time for the respective AS and Doze states. As the traffic load increases beyond 0.65 , the savings drop to less than $15 \%$ and the saving trends appear to be inverted as the WSM scheme shows comparatively highest savings followed by the AWSM and CSM schemes. This is because of the higher Active state times, minimum AS and Doze state times, and increased initialization time and awake times of the ONTs.

The CSM scheme leads to highest DS and US delays compared to both the AWSM and WSM schemes. From Figures 9-11 it can be seen that the AWSM scheme shows almost the same delays as that of the WSM scheme for all the traffic classes. The CSM scheme shows up to $12 \%, 10 \%, 24 \%$, and $24 \%$ higher DS and US delay for T1, T2, T3, and T4 traffic classes, respectively, compared to the AWSM scheme with only $5 \%$ higher energy savings.

In addition to US and DS delays, the delay variance is also an important parameter to be considered for the network performance. Especially for the delay sensitive network services, the ITU PON standard requires the delay variance to be less than $1 \mathrm{~ms}$.

The delay variance results recorded from the simulation are shown in Figures 11-13. All Watchful schemes show lesser delay variance for all the traffic classes compared to CSM. QWSM shows least delay variance while WSM and AWSM schemes show results that are close to overlapping. Both the US and DS variance is observed to be quite low for all traffic loads and does not exceed $1 \mathrm{~ms}$.

Therefore, it can be fairly concluded from all the results discussed above that the AWSM scheme is the most suitable energy conservation scheme for ITU compliant PONs, as it provides very high energy savings comparable to the CSM scheme and much better quality of service owing to its lower US and DS delay and delay variance.

\section{Conclusions}

This study presents an adaptive watchful sleep mode scheme that improves the existing ITU compliant watchful sleep process. The proposed scheme minimizes the ONT ON time to increase the ONT AS state time during the Watch state without compromising the US quality of service. This is achieved by choosing the duration and occurrence of the $T_{O N}$ time in accordance with the DS traffic arrival rate $\beta_{D S}$. The study results show a useful 
energy savings of $9 \%$ compared to the standard WSM process. In our future work we will investigate the impact of the DBA process on the AWSM scheme.

Author Contributions: All the authors have contributed to this research study; their main contributions follow: conceptualization, testbed implementation, software implementation, and validation, R.A.B. and A.A.; original draft preparation and formal analysis, M.F.; writing-review and editing, B.R. All authors have read and agreed to the published version of the manuscript.

Funding: This research was funded by University Malaysia Sabah.

Institutional Review Board Statement: Not Applicable.

Informed Consent Statement: Not Applicable.

Data Availability Statement: This study did not report any data.

Conflicts of Interest: The authors declare no conflict of interest.

\section{References}

1. Sharma, N.; Agrawal, S.; Kapoor, V. Performance optimization of OADM based DP-QPSK DWDM optical network with $37.5 \mathrm{GHz}$ channel spacing. Opt. Switch. Netw. 2021, 40, 100606. [CrossRef]

2. Do, D.T.; Nguyen, T.T.T. Impacts of imperfect SIC and imperfect hardware in performance analysis on AF non-orthogonal multiple access network. Telecommun. Syst. 2019, 72, 579-593. [CrossRef]

3. International Telecommunication Union. Measuring Digital Development Facts and Figures 2020; International Telecommunication Union: Geneva, Switzerland, 2020.

4. Obite, F.; Jaja, E.T.; Ijeomah, G.; Jahun, K.I. The evolution of Ethernet Passive Optical Network (EPON) and future trends. Optik 2018, 167, 103-120. [CrossRef]

5. $\quad$ Effenberger, F. PON Convergence. IEICE Trans. Commun. 2018, E101-B, 947-951. [CrossRef]

6. Shen, C. Experiences and Future Perspective of China Telecom on Optical Access Networks. In Proceedings of the IEEE Optical Fiber Communications Conference and Exhibition (OFC 2017), Los Angeles, CA, USA, 19-23 March 2017; pp. 26-28.

7. Nesset, D. PON Roadmap [Invited]. J. Opt. Commun. Netw. 2017, 9, A71-A76. [CrossRef]

8. Yi, L.; Ji, H.; Li, Z.; Li, X.; Li, C.; Yang, Q.; Xue, L.; Wang, X.; Wang, S.; Yang, Y.; et al. Field-Trial of Real-Time 100 Gb/s TWDM-PON Based on 10G-Class Optical Devices. In Proceedings of the 42nd European Conference and Exhibition on Optical Communications, Dusseldorf, Germany, 18-22 September 2016; pp. 688-697.

9. $\quad$ ITU-T. ITU-T 40-Gigabit-Capable Passive Optical Networks 2 (NG-PON2): Physical Media Dependent (PMD) Layer Specification G.989.2; International Telecommunication Union: Geneva, Switzerland, 2019; Volume 2.

10. Shi, B.; Zhang, Y. A novel algorithm to optimize the energy consumption using iot and based on ant colony algorithm. Energies 2021, 14, 1709. [CrossRef]

11. Oliveira, T.F.; Xavier-De-souza, S.; Silveira, L.F. Improving energy efficiency on SDN control-plane using multi-core controllers. Energies 2021, 14, 3161

12. Dourado, D.M.; Ferreira, R.J.L.; Rocha, M.D.; Duarte, U.R. Energy consumption and bandwidth allocation in passive optical networks. Opt. Switch. Netw. 2018, 28, 1-7. [CrossRef]

13. Morley, J.; Widdicks, K.; Hazas, M. Energy Research \& Social Science Digitalisation, energy and data demand: The impact of Internet traffic on overall and peak electricity consumption. Energy Res. Soc. Sci. 2018, 38, 128-137.

14. Dabaghi-Zarandi, F.; Movahedi, Z. An energy-efficient algorithm based on sleep-scheduling in IP backbone networks. Int. J. Commun. Syst. 2017, 30, 1-8. [CrossRef]

15. ITU-T Standard, G.987.3; 10-Gigabit-Capable Passive Optical Networks (XG-PON): Transmission Convergence (TC) Layer Specification. ITU-T: Geneva, Switzerland, 2014; 1-146.

16. Butt, R.A.; Ashraf, M.W.; Anwar, M.Y.; Anwar, M. Receiver ON Time Optimization for Watchful Sleep Mode to Enhance Energy Savings of 10-Gigabit Passive Optical Network. Tech. J. Univ. Eng. Technol. Taxila 2018, 23, 72-80.

17. Butt, R.A.; Idrus, S.M.; Zulkifli, N.; Ashraf, M.W. A survey of energy conservation schemes for present and next generation passive optical networks. J. Commun. 2018, 13, 129-138. [CrossRef]

18. Iiyama, N.; Kimura, H.; Hadama, H. A Novel WDM-based Optical Access Network with High Energy Effeciency Using Elastic OLT. In Proceedings of the Optical Network Design and Modeling (ONDM), Kyoto, Japan, 1-3 February 2010; pp. 1-6.

19. Zhang, J.; Wang, T.; Ansari, N. Designing energy-efficient optical line terminal for TDM passive optical networks. In Proceedings of the 34th IEEE Sarnoff Symposium (SARNOFF), Princeton, NJ, USA, 3-4 May 2011; pp. 1-5.

20. Butt, R.A.; Ashraf, M.W.; Faheem, M.; Idrus, S.M. Processing efficient frame structure for passive optical network (PON). Opt. Switch. Netw. 2018, 30, 85-92. [CrossRef]

21. Sankaran, G.C.; Sivalingam, K.M. ONU buffer reduction for power efficiency in Passive Optical Networks. Opt. Switch. Netw. 2013, 10, 416-429. [CrossRef] 
22. Wong, E. Energy Efficient Passive Optical Networks with Low Power VCSELs. In Proceedings of the Annual Wireless and Optical Communications Conference (WOCC), Kaohsiung, Taiwan, 19-21 April 2012; pp. 48-50.

23. Suvakovic, D.; Chow, H.; Anthapadmanabhan, N.P.; van Veen, D.T.; van Wijngaarden, A.J.; Ayhan, T.; van Praet, C.; Torfs, G.; Yin, X.; Vetter, P. A Low-Energy Rate-Adaptive Bit-Interleaved Passive Optical Network. IEEE J. Sel. Areas Commun. 2014, 32, 1552-1565. [CrossRef]

24. Lingas, N.; Uddin, M.R. Sleep Mode on Delay Sensitive Traffic on Optical Network Unit. In Proceedings of the 23rd IEEE International Conference on Advanced Communication Technology (ICACT), PyeongChang, Korea, 7-10 February 2021 ; pp. 407-410.

25. Nikoukar, A.; Hwang, I.S.; Wang, C.J.; Ab-Rahman, M.S.; Liem, A.T. A SIEPON based transmitter sleep mode energy-efficient mechanism in EPON. Opt. Fiber Technol. 2015, 23, 78-89. [CrossRef]

26. Alaelddin, F.Y.M.; Newaz, S.H.S.; L-Hazemi, F.A.; Choi, J.K. Grant management procedure for energy saving TDM-PONs. Opt. Fiber Technol. 2018, 40, 118-129. [CrossRef]

27. Maneyama, Y.; Kubo, R. QoS-Aware Cyclic Sleep Control With Proportional-Derivative Controllers for Energy-Efficient PON Systems. J. Opt. Commun. Netw. 2017, 6, 1048. [CrossRef]

28. Nikoukar, A.; Hwang, I.-S.; Andrew Fernando Pakpahan Andrew Tanny Liem. Two-phase ONU Doze Mode Energy-saving Mechanism in EPON. In Proceedings of the International MultiConference of Engineers and Computer Scientists, Hong Kong, China, 16-18 March 2016.

29. Nikoukar, A.; Hwang, I.-S.; Liem, A.T.; Su, Y.-M. A new ONU-initiated doze mode energy-saving mechanism in EPON. In Proceedings of the International MultiConference of Engineers and Computer Scientists, Hong Kong, China, 18-20 March 2015; Volume 1, pp. 1-5.

30. Hirafuji, R.O.C.; Dhaini, A.; Khotimsky, D. Energy efficiency analysis of the Watchful Sleep mode in next-generation passive optical networks. In Proceedings of the IEEE Symposium on Computers and Communication (ISCC), Messina, Italy, 27-30 June 2016; pp. 689-695.

31. Zhu, M.; Zeng, X.; Lin, Y.; Sun, X. Modeling and Analysis of Watchful Sleep Mode With Different Sleep Period Variation Patterns in PON Power Management. J. Opt. Commun. Netw. 2017, 9, 803. [CrossRef]

32. Zin, A.M.; Idrus, S.M.; Ramli, A.; Butt, R.A.; Atan, F.M.; Ismail, N.A. Performance Evaluation of XG-PON with DBA BasedWatchful Sleep Mode. In Proceedings of the IEEE 7th International Conference on Photonics (ICP), Langkawi, Malaysia, 9-11 April 2018; pp. 6-8.

33. Pakpahan, A.F.; Hwang, I.-S.; Liem, A.T. Enabling Agile Software-Defined and NFV based Energy-Efficient Operations in TWDM-PON. In Proceedings of the 7th International Conference on Cyber and IT Service Management (CITSM 2019), Jakarta, Indonesia, 6-8 November 2019; pp. 1-7.

34. Garg, S.; Dixit, A. Novel bandwidth and wavelength allocation algorithm for energy efficiency in TWDM-PON. In Proceedings of the International Conference on Transparent Optical Networks, Angers, France, 9-13 July 2019; pp. 1-4.

35. Dixit, A.; Lannoo, B.; Colle, D.; Pickavet, M.; Demeester, P. ONU power saving modes in next generation optical access networks: Progress, efficiency and challenges. Opt. Express 2012, 20, B52-B63. [CrossRef]

36. Dixit, A.; Lannoo, B.; Colle, D.; Pickavet, M.; Demeester, P. Energy efficient dynamic bandwidth allocation for Ethernet passive optical networks: Overview, challenges, and solutions. Opt. Switch. Netw. 2015, 18, 169-179. [CrossRef]

37. Rayapati, B.R.; Rangaswamy, N. Heuristic polling sequence to enhance sleep count of EPON. Front. Optoelectron. 2019, 12, 422-432. [CrossRef]

38. Zhu, M.; Li, G.; Zhang, S.; Gu, J.; Chen, B.; Sun, Q. Pairwise-combination-based dba scheme for energy-efficient low-latency tdm-pons. In Proceedings of the 2018 10th International Conference on Advanced Infocomm Technology, ICAIT, Stockholm, Sweden, 12-15 August 2018; pp. 128-132.

39. Khalili, H.; Rinc, D.; Sallent, S. An Energy-Efficient Distributed Dynamic Bandwidth Allocation Algorithm for Passive Optical Access Networks. Opt. Eng. 2020, 12, 2264. [CrossRef]

40. Hirafuji, R.O.C.; Cunha, K.B.; Campelo, D.R.; Dhaini, A.R.; Khotimsky, D.A. The Watchful Sleep Mode: A New Standard for Energy Efficiency in Future Access Networks. IEEE Commun. Mag. 2015, 58, 150-157. [CrossRef]

41. Zhu, M.; Zeng, X.; Lin, Y.; Sun, X. Modeling and analysis for watchful sleep mode in PON power management. In Proceedings of the 15th International Conference on Optical Communications and Networks, Hangzhou, China, 24-27 September 2016; pp. 15-17.

42. Rayapati, B.R.; Rangaswamy, N.; Shaik, E.H. Investigation on power efficiency of gpon with heterogeneous traffic. In Proceedings of the 2017 Progress in Electromagnetics Research Symposium-Fall (PIERS-FALL), Singapore, 19-22 November 2017; pp. $2603-2607$.

43. Butt, R.A.; Idrus, S.M.; Zulkifli, N. Comparative analysis of cyclic and watchful sleep modes for GPON. In Proceedings of the 2016 IEEE 6th International Conference on Photonics, ICP, Kuching, Malaysia, 14-16 March 2016.

44. Zeng, X.; Zhu, M.; Wang, L.; Sun, X. Optimization of sleep period in watchful sleep mode for power-efficient passive optical networks. Photonic Netw. Commun. 2017, 35, 300-308. [CrossRef]

45. Valcarenghi, L. Cognitive PONs: A Novel Approach toward Energy Efficiency. In Proceedings of the Asia Communications and Photonics Conference, Guangzhou, China, 7-10 November 2012; pp. 2-4.

46. Butt, R.A.; Idrus, S.M.; Qureshi, K.N.; Shah, P.M.A.; Zulkifli, N. An energy efficient cyclic sleep control framework for ITU PONs. Opt. Switch. Netw. 2018, 27, 7-17. [CrossRef]

47. Zhu, M.; Gu, J.; Li, G. PWC-PON: An Energy-Efficient Low-Latency DBA Scheme for Time Division Multiplexed Passive Optical Networks. IEEE Access 2020, 8, 206848-206865. [CrossRef] 
48. Butt, R.A.; Faheem, M.; Ashraf, M.W.; Arfeen, A.; Memon, K.A.; Khawaja, A. Sleep-aware wavelength and bandwidth assignment scheme for TWDM PON. Opt. Quantum Electron. 2021, 53, 295. [CrossRef]

49. Han, M.S.; Yoo, H.; Lee, D.S. Development of Efficient Dynamic Bandwidth Allocation Algorithm for XGPON. ETRI J. 2013, 35, 18-26. [CrossRef] 